\title{
Robertsonian rearrangements in the reef fish Chromis (Perciformes, Pomacentridae) involving chromosomes bearing 5s rRNA genes
}

\section{Wagner F. Molina ${ }^{1}$ and Pedro M. Galetti-Jr ${ }^{2}$}

\author{
${ }^{1}$ Departamento de Biologia Celular e Genética, Centro de Biociências, Universidade Federal \\ do Rio Grande do Norte, Campus Universitário, Natal, RN, Brazil. \\ ${ }^{2}$ Departamento de Genética e Evolução, Universidade Federal de São Carlos, São Carlos, SP, Brazil.
}

\begin{abstract}
Cytogenetic studies were done on three Pomacentridae species of the genus Chromis. The karyotype of $C$. multilineata consisted of 48 acrocentric chromosomes $(\mathrm{FN}=48)$, C. insolata had $2 \mathrm{n}=46-47(3-4 \mathrm{M}+6 \mathrm{SM}+36-38 \mathrm{~A}$; $\mathrm{FN}=56)$ and $C$. flavicauda had $2 \mathrm{n}=39(9 \mathrm{M}+6 \mathrm{SM}+24 \mathrm{~A} ; \mathrm{FN}=54)$. Robertsonian polymorphisms were detected in $C$. insolata and $C$. flavicauda. All three species had small heterochromatic blocks restricted to centromeric regions. Nucleolar organizer regions (NORs) were detected in the telomeric position of a medium acrocentric chromosome pair in $C$. multilineata and in non-homologous chromosomes in both $C$. flavicauda and $C$. insolata. FISH with a telomeric probe detected no internal telomeric sequences in $C$. flavicauda and $C$. insolata. 5S rRNA genes were observed in a pericentromeric region of two large metacentric chromosome pairs in $C$. flavicauda and two large acrocentric pairs in $C$. insolata. The karyotype structure and the number and location of the $5 S$ rDNA loci in these two species indicated that the $5 \mathrm{~S}$ rRNA-bearing acrocentric chromosomes were directly involved in the origin of the polymorphisms observed. These data reinforce the idea that Robertsonian rearrangements have been involved in molding the karyotype in the subfamily Chrominae.
\end{abstract}

Key words: Chromis, FISH, polymorphism, Robertsonian rearrangements, 5S rDNA, telomeric sequences.

Received: March 5, 2002; accepted: July 31, 2002.

\section{Introduction}

Genetic differentiation in populations of reef fishes has been shown by allozyme (Knowlton et al., 1993) and mitochondrial DNA (Knowlton et al., 1993; Shulman and Bermingham, 1995). In contrast, several groups of these fish have quite a conservative chromosomal structure, even when large geographical distances are considered (for a review, see Brum and Galetti, 1997). Robertsonian chromosomal rearrangements, such as centric fusion and fission, have been identified as important mechanisms in the karyotype differentiation of distinct fish groups (Hartley and Horne, 1984; Amores et al., 1990).

In reef fish belonging to the Pomacentridae, centric fusion has been described either as a polymorphic condition, as observed in the genus Dascyllus (Ojima and Kashiwagi, 1981), or established in derived karyotypes, as detected in two species of Chrysiptera (Takai and Ojima,

Send correspondence to W.F.M. Departamento de Biologia Celular e Genética, Centro de Biociências, Universidade Federal do Rio Grande do Norte, Campus Universitário, 59078-970 Natal, RN, Brasil. E-mail: molinawf@yahoo.com.br.
1995). Robertsonian chromosomal rearrangements have also been implicated in the origin of novel, multiple sex chromosome systems in fish (Brum et al., 1992) and in some cases, may contribute to the occurrence of genetically isolated populations.

In this paper, we describe the karyotype, heterochromatin pattern and nucleolar organizer regions in three Pomacentridae, Chromis multilineata, $C$. insolata and $C$. flavicauda. In addition, telomeric- and 5S rDNA probes were used in fluorescence in situ hybridization (FISH), to identify the chromosomes involved in the Robertsonian rearrangements observed in C. insolata and C. flavicauda.

\section{Materials and Methods}

Cytogenetic analyses were done on three Pomacentridae species from two regions in Brazil. Chromis multilineata (1 juvenile and 3 females) were collected on the coast of the State of Bahia and C. insolata (4 juveniles and 4 females) and C. flavicauda (2 males) were obtained from the State of Espírito Santo. Chromosomal preparations were obtained as described by Bertollo et al. (1978). 
mitosis was stimulated by the intraperitoneal injection of yeast glucose solution (Lee and Elder, 1980). Ag-NORs and C-bands were detected as described by Howell and Black (1980) and Sumner (1972), respectively.

Fluorescence in situ hybridization (FISH) using chromosomes of C. insolata and C. flavicauda was done as described by Martins and Galetti (1999). Telomeric sites were detected using the telomeric probe (TTAGGG) $)_{\mathrm{n}}$ of Xenopus laevis, in either high or low formamide stringency conditions $(70 \%$ or $30 \%$, respectively). The chromosomal localization of 5S rDNA was determined using a pBSIIKS recombinant plasmid containing the $5 \mathrm{~S}$ rRNA gene plus its non-transcribed spacer (NTS) obtained from the fish Leporinus elongatus (Martins and Galetti, 1999). Both probes were labeled with biotin-11-dUTP by nick translation according to the manufacturer's instructions (Bionick $^{\mathrm{TM}}$ Labeling System, Gibco). The 5S rDNA loci and telomeric sites were visualized using biotinylated antiavidin antibody and an avidin-fluorescein isothiocyanate (FITC) conjugate. Metaphases were examined with an Olympus BX50 epifluorescence microscope and photographed with 400 ASA Kodak Ektachrome film.

\section{Results}

Chromis multilineata had an invariant karyotype of 48 acrocentric chromosomes, with a fundamental number (FN) of 48 (Figure 1a). In C. insolata, two cytotypes were observed, each differing in the number of metacentric chromosomes. Four individuals showed $2 \mathrm{n}=46(4 \mathrm{M}+6 \mathrm{SM}+$ $36 \mathrm{~A} ; \mathrm{FN}=56)$ and four had $2 \mathrm{n}=47(3 \mathrm{M}+6 \mathrm{SM}+38 \mathrm{~A} ; \mathrm{FN}=$ 56) (Figure 1b). The two individuals of C. flavicauda showed a karyotype with $2 \mathrm{n}=39$ and $\mathrm{FN}=54(9 \mathrm{M}+$ 6SM+24A) (Figure 1c). Both C. insolata and C. flavicauda had large metacentric chromosomes that were almost double the size of the other chromosomes of the complement. A peculiar radial configuration of the chromosomes was frequently observed in the metaphase figures of all the species analyzed (Figure 1d, e).

Ag-NORs were detected on the short arm of a medium-size acrocentric chromosomal pair in Chromis multilineata (Figure 1a) and in the telomeric portion of the short arm of two non-homologous acrocentric chromosomes of $C$. insolata (Figure 1b). In the latter species, an additional NOR was occasionally observed in the proximal region on the long arm of a large acrocentric chromosome. In C. flavicauda, NORs were detected at the telomeric position of distinct chromosomal pairs. One site was located on the short arm of a small acrocentric chromosome, while the other was located on the long arm of a small submetacentric (Figure 1c).

All three species showed a common C-banding pattern characterized by small centromeric blocks of heterochromatin on most chromosomes (Figure 2a, b, c).

At low stringency, the telomeric probe gave conspicuous signals on the terminal portion of practically all $C$.
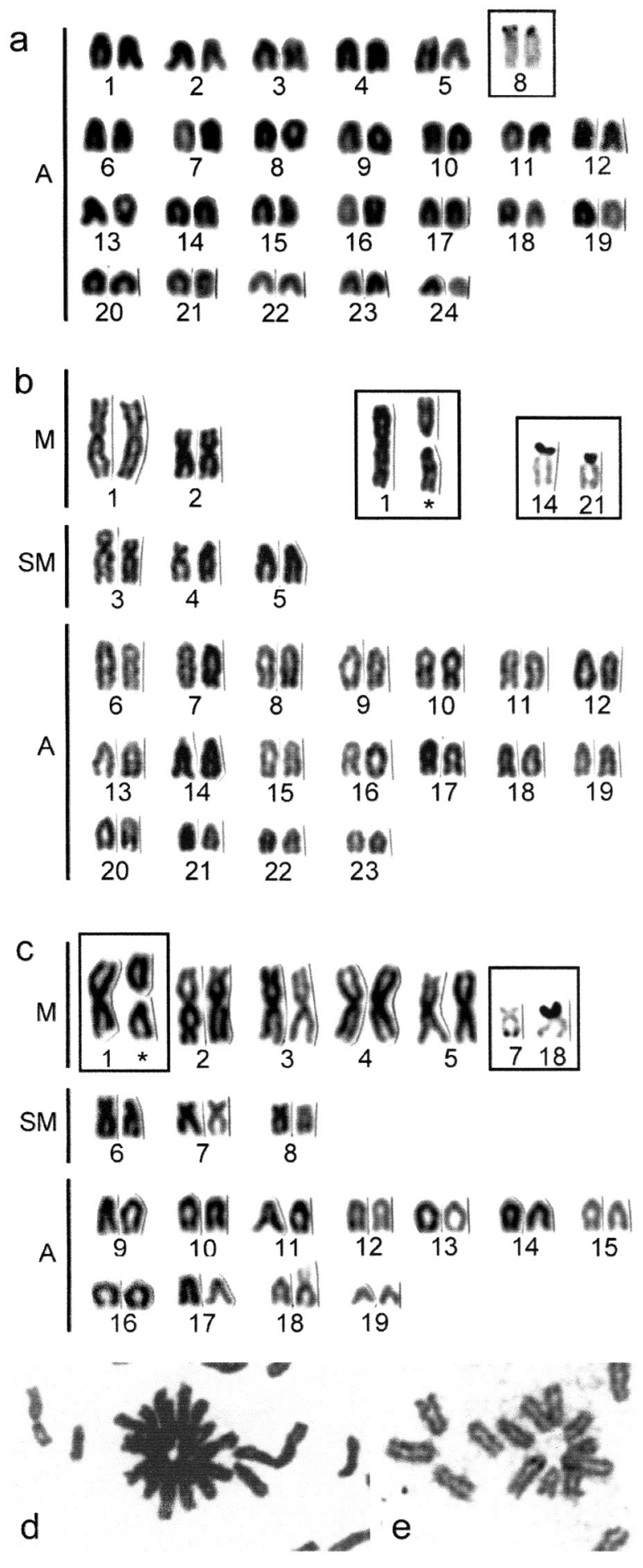

Figure 1 - Giemsa stained karyotypes of Chromis multilineata (a), C. insolata (b) and C. flavicauda (c) with chromosomes related to centric fusion indicated in the larger boxes. The Ag-NOR bearing chromosomes are in the smaller boxes. Partial metaphases showing the radial configuration of acrocentric chromosomes in C. flavicauda (d) and C. insolata (e).

insolata and C. flavicauda chromosomes (Figure 3c, d). The fluorescent signals were lower under high stringency conditions (data not shown). The 5S rDNA clusters were 


\section{a}

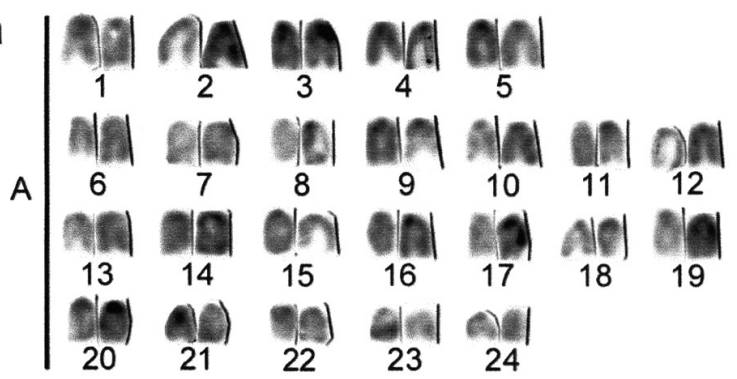

b
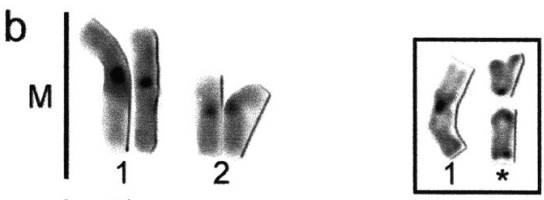

SM
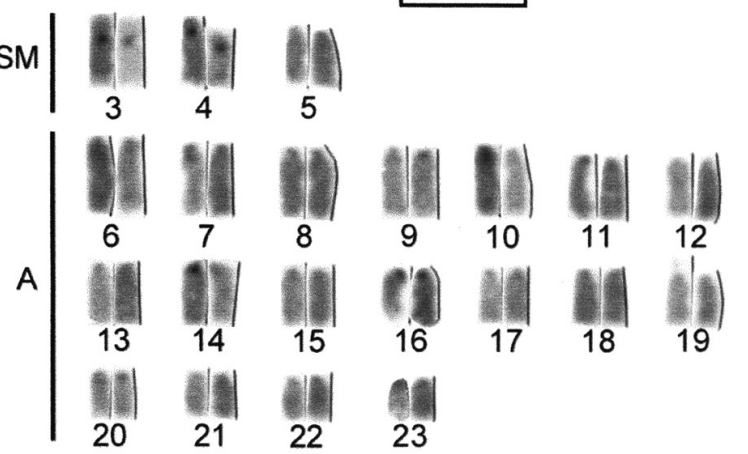

9
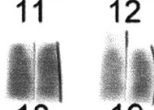

C

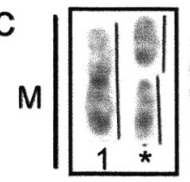

SM
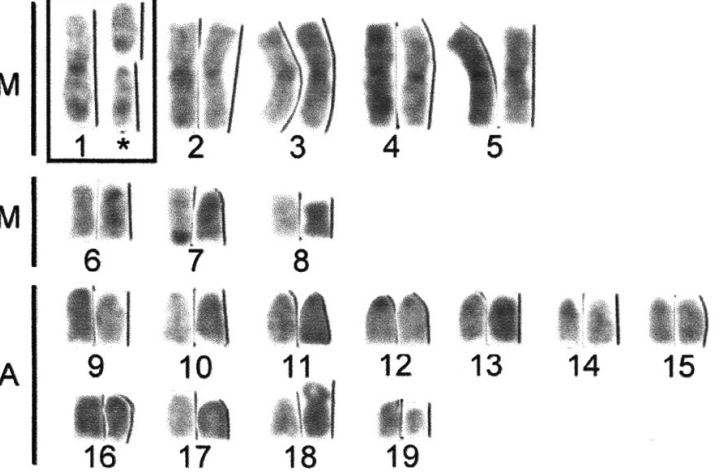

Figure 2 - C-banded karyotypes of Chromis multilineata (a), C. insolata (b) and C. flavicauda (c) with chromosomes related to centric fusion indicated in the boxes.

detected by FISH in the telomeric region of two large acrocentric chromosomal pairs in C. insolata (Figure 3e) and in the pericentromeric region of two large metacentric chromosomes, comparable to pairs 2 and 3 , of $C$. flavicauda (Figure 3f).

\section{Discussion}

Robertsonian polymorphisms are important sources of karyotype diversification in several Perciformes groups, including the Pomacentridae (Ojima and Kashiwagi, 1981), Gobiidae (Thode et al., 1985; Vitturi and Catalano, 1989;
Amores et al., 1990; Caputo et al., 1997) and Cichlidae (Martins et al., 1995).

Most Pomacentridae species often show a numerically conserved karyotype of 48 chromosomes, with differences in the chromosome formula $(\mathrm{FN}=48-90)$ probably being related to the occurrence of pericentric inversions during karyotype diversification (Takai and Ojima, 1987). In contrast, the Chrominae, which includes the genera Acanthochromis, Azurina, Chromis and Dascyllus, shows a particular trend towards Robertsonian polymorphisms. The diploid number can vary between $2 \mathrm{n}=47-48$ in Dascyllus trimaculatus, $2 \mathrm{n}=34-37$ in D. reticulatus, and $2 \mathrm{n}=27-33$ in D. aruanus (Ojima and Kashiwagi, 1981). Asynchronic hermaphroditism is common among these fishes and the likelihood that these divergent cytotypes are associated with multiple sexual chromosomes can be excluded (Ojima and Kashiwagi, 1981).

Fish species of inter-oceanic distribution, from the Caribbean reefs and from the Gulf of California in the Pacific Ocean, had a Pleistocene radiation (Shulman and Bermingham, 1995; Ward, 1995), indicating that the changes which occurred in this period were drastic enough to affect distinct groups with wide or narrow migratory capacities. At the beginning of the Pleistocene 700,000 years ago, the South American continent suffered a depression and the ocean overflowed, a condition that persisted throughout the Quaternary. Historic oceanographic events (1-5 MY) appear to have produced behavioral isolation that has affected the evolution and biogeographical patterns of some fish populations along the Brazilian coastline (Goodbred and Graves, 1996). During periods of regression, sequential bottleneck populations may have been generated by a high loss of habitats (Shulman and Bermingham, 1995; Ward, 1995), thus contributing to the current differentiation along the coastline.

Previous studies of the genus Chromis revealed that C. chromis had $2 \mathrm{n}=48$ and $\mathrm{FN}=48$ (Alvarez et al., 1980), C. chrysura had $2 \mathrm{n}=48$ and $\mathrm{FN}=50$, and $C$. caerulea had $2 \mathrm{n}=48$ and $\mathrm{FN}=48$ (Ojima and Kashiwagi, 1981), indicating the occurrence of a highly conserved karyotype among these fishes. The reduction in chromosome number and the presence of distinctive metacentric chromosomes in $C$. insolata and C. flavicauda may have resulted from centric fusions. Such polymorphism could be transitory and represent a step in an evolutionary process such as karyotypic orthoselection (sensu White, 1973) among Chrominae species.

The radial chromosomal configurations observed in several metaphases of Chromis have also been reported in other fish species (Aguilar et al., 1998). This configuration may be the remains of a later arrangement of these chromosomes during the preceding interphase, which could have facilitated chromosomal exchange among non-homologous chromosomes (Aguilar et al., 1998). 

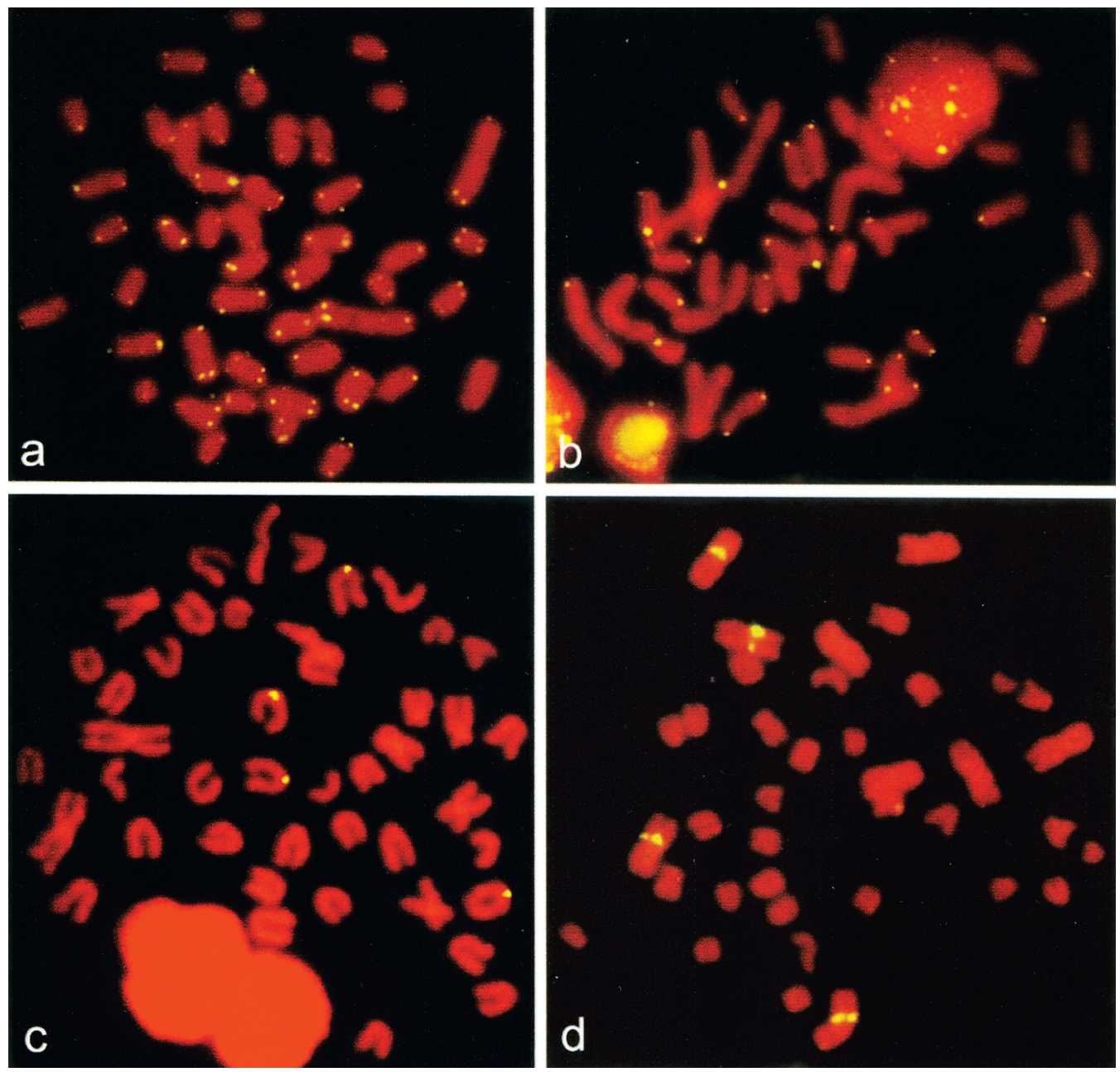

Figure 3 - FISH using a telomeric sequence probe in C. insolata (a) and C. flavicauda (b). The results obtained using a 5S rDNA probe in these same species are shown in (c) and (d), respectively.

The NOR distribution at the end of acrocentric chromosomes in C. flavicauda and C. insolata was quite similar to the distribution pattern observed in other Chrominae species (Takai and Ojima, 1995). The detection of NOR sites in non-homologous chromosomes in the studied species may also indicate increased plasticity of the chromosomal complement of these fishes, resulting in extensive polymorphism such as described in this study.

The pronounced conservation of telomeric sequences among vertebrates (Meyne et al., 1989) was further demonstrated by the positive hybridization of the Xenopus telomeric probe with the chromosomes of C. flavicauda and $C$. insolata. Internal telomeric sites were not observed in either species, regardless of the stringency conditions for hybridization. The failure to detect internal telomeric sequences does not necessarily refute the hypothesis of centric fusions in the karyotype of these species. Telomeric sequences could have been eliminated by subsequent modifications or may be too small to be detected by cytogenetic methods (Meyne et al., 1990; Nanda et al., 1995). In some cases, telomeric sequences can be interspersed with repeti- tive DNA regions (Garrido-Ramos et al., 1998) and can occur within or near heterochromatic blocks (Meyne et al., 1990; Abuín et al., 1996). The absence of interstitial heterochromatic blocks in Chromis could account for the lack of ectopic sequences in fused chromosomes.

In contrast to the telomeric sequences, the FISH experiments based on 5S rDNA in C. flavicauda and $C$. insolata corroborated the hypothesis of centric fusion in the genus Chromis. In both species, the $5 \mathrm{~S}$ and $45 \mathrm{~S}$ rDNA loci occurred on different chromosomes. This is the condition most frequently observed in fish and reflects the independent evolution of distinct genes subjected to diverse selection pressures (Martins and Galetti, 1999). The interstitial location of 5S rDNA sites on two metacentric pairs (pairs 2 and 3) of C. flavicauda may be indicative of a sequential stage of non-homologous fusion involving acrocentric chromosomes of $C$. insolata. Whether these genes were actively involved in fusion events remains unknown. However, the current chromosome mapping of 5S rRNA genes reinforces the hypothesis that Robertsonian rearrangements 
have occurred during karyotype diversification in this group of fish.

\section{Acknowledgements}

The authors thank Coordenação de Aperfeiçoamento de Pessoal de Nível Superior (CAPES) and Conselho Nacional de Desenvolvimento Científico e Tecnológico (CNPq) for the financial support.

\section{References}

Abuín M, Martínez P and Sánchez L (1996) Localization of the repetitive telomeric sequence (TTAGGG) in four salmonid species. Genome 39:1035-1038.

Aguilar CT, Corrêa MMO and Galetti PM Jr (1998) Chromosome associations by centromeric heterochromatin in marine fishes. Chromosome Sci 2:73-76.

Alvarez MC, Cano J and Thode G (1980) DNA content and chromosome complement of Chromis chromis (Pomacentridae, Perciformes). Caryologia 33:267-274.

Amores A, Giles V, Thode G and Alvarez MC (1990) Adaptative character of a Robertsonian fusion in chromosomes of the fish Gobius paganellus (Pisces, Perciformes). Heredity 65:150-155.

Bertollo LAC, Takahashi CS and Moreira FO (1978) Cytotaxonomic considerations on Hoplias lacerdae (Pisces, Erythrinidae). Braz J Genet 1:103-120.

Brum MJI and Galetti PM Jr (1997) Teleostei ground plan karyotype. J Comp Biol 2:91-102.

Brum MJI, Galetti PM Jr, Corrêa MMO and Aguilar CT (1992) Multiple Sex chromosomes in South Atlantic fish, Brevoortia aurea, Clupeidae. Braz J Genet 15:547-553.

Caputo V, Marchegiani F, Sorice M and Olmo E (1997) Heterochromatin heterogeneity and chromosome variability in four species of gobiid fishes (Perciformes:Gobiidae). Cytogenet Cell Genet 79:266-271.

Garrido-Ramos Ma, Herrán R, Ruiz Rejón C and Ruiz Rejón M (1998) A satellite DNA of the Sparidae family (Pisces, Perciformes) associated with telomeric sequences. Cytogenet Cell Genet 83:3-9.

Goodbred CO and Graves JE (1996) Genetic relationships among geographically isolated populations of bluefish (Pomatomus saltatrix). Mar Freshwater Res 47:347-355.

Hartley SE and Horne MT (1984) Chromosome relationships in the genus Salmo. Chromosoma 90:229-237.

Howell WM and Black A (1980) Controlled silver staining of nucleolus organizer regions with protective colloidal developer: 1- Step Method. Experientia 36:1014-1015.

Knowlton N, Weith LA, Solórzano LA, Mills DEK and Bermingham E (1993) Divergence in proteins, mitochon- drial DNA and reproductive compatibility across the Isthmus of Panama. Science 260:1629-1632.

Lee MR and Elder FFB (1980) Yeast stimulation of bone marrow mitosis for cytogenetic investigations. Cytogenet Cell Genet 26:36-40.

Martins C and Galetti PM Jr (1999) Chromosomal localization of 5S rDNA genes in Leporinus fish (Anostomidae, Characiformes). Chromosome Res 7:363-367.

Martins IC, Portella-Castro LB and Julio HF Jr (1995) Chromosome analysis of Cichlidae family (Pisces - Perciformes) from the Parana river. Cytologia 60:223-231.

Meyne J, Baker RJ, Hobart HH, Hsu TC, Ryder AO, Ward OG, Wiley JE, Wurster-Hill DH, Yates TL and Moyzis RK (1990) Distribution of non-telomeric sites of the (TTAGGG) $)_{\mathrm{n}}$ telomeric sequence in vertebrate chromosomes. Chromosoma 99:3-10.

Meyne J, Ratliff RL and Moyzis RK (1989) Conservation of the human telomere sequence (TTAGGG)n among vertebrates. Proc Natl Acad Sci USA 86:7049-7053.

Nanda I, Schneider-Rasp, Winking H and Schmid M (1995) Loss of telomeric sites in the chromosomes of Mus musculus domesticus (Rodentia:Muridae) during Robertsonian rearrangements. Chromosome Res 3:399-409.

Ojima Y and Kashiwagi E (1981) Chromosomal evolution associated with Robertsonian fusion in the genus Dascyllus (Chromininae, Pisces). Proc Jpn Acad 57b:368.

Ojima Y (1983) Fish cytogenetics. In: Sharma AK and Sharma A (eds) Chromosomes in evolution of eukaryotic groups. CRC Press, Boca Raton, 254 p.

Shulman MA and Bermingham E (1995) Early life histories, ocean currents, and the population genetics of Caribbean reef fishes. Evolution 49:897-910.

Sumner AT (1972) A simple technique for demonstrating centromeric heterochromatin. Exp Cell Res 75:304-306.

Takai A and Ojima Y (1987) Comparative studies of karyotypes and distribution of nucleolus organizer regions in Pomacentrid fish. Proc Jpn Acad 63B:17-20.

Takai A and Ojima Y (1995) Chromosome evolution associated with Robertsonian rearrangements in Pomacentrid fish (Perciformes). Cytobios 84:103-110.

Thode G, Giles V and Alvarez MC (1985) Multiple chromosome polymorphism in Gobius paganellus (Teleostei, Perciformes). Heredity 54:3-7.

Vitturi R and Catalano E (1989) Multiple chromosome polymorphism in the gobiid fish Gobius niger jozo L. 1758 (Pisces, Gobiidae). Cytologia 54:231-235.

Ward RD (1995) Population genetics of tunas. J Fish Biol 47:259-280.

White MJD (1973) Animal Cytology and Evolution. Cambridge University Press, Cambridge, 961p. 